\title{
Effect of ethylic alcohol on attentive functions involved in driving abilities
}

\author{
U. BIVONA', S. GARBARINO², J. RIGON³, M.G. BUZZI', G. ONDER ${ }^{4}$, M. MATTEIS', \\ S. CATANI', M. GIUSTINI ${ }^{5}$, GL. MANCARDI', R. FORMISANO' \\ ' IRCCS Fondazione Santa Lucia Rehabilitation Hospital, Italy; ${ }^{2}$ Department of Neuroscience, \\ Ophthalmology and Genetics, University of Genoa, Italy; ${ }^{3}$ San Camillo Hospital, Lido-Venice, Italy; \\ ${ }^{4}$ Catholic University, Rome, Italy; ${ }^{5}$ sstituto Superiore di Sanità, Environment and Trauma Unit, Rome, Italy
}

\section{A B S T R A C T}

The burden of injuries due to drunk drivers has been estimated only indirectly. Indeed, alcohol is considered one of the most important contributing cause of car crash injuries and its effect on cognitive functions needs to be better elucidated. Aims of the study were i) to examine the effect of alcohol on attentive abilities involved while driving, and ii) to investigate whether Italian law limits for safe driving are sufficiently accurate to prevent risky behaviours and car crash risk while driving. We conducted a cross-over study at IRCCS Fondazione Santa Lucia Rehabilitation Hospital in Rome. Thirty-two healthy subjects were enrolled in this experiment. Participants were submitted to an attentive test battery assessing attention before taking Ethylic Alcohol (EA-) and after taking EA (EA+). In the EA+ condition subjects drank enough wine until the blood alcohol concentration, measured by means of Breath Analyzer, was equal to or higher than $0,5 \mathrm{~g} / \mathrm{l}$. Data analysis revealed that after alcohol assumption, tonic and phasic alertness, selective, divided attention and vigilance were significantly impaired when BAC level was at least $0.5 \mathrm{~g} / \mathrm{l}$. These data reveal that alcohol has a negative effect on attentive functions which are primarily involved in driving skills and that Italian law limits are adequate to prevent risky driving behaviour.

\author{
Key words \\ Ethylic alcohol $\bullet$ Attentive functions $\bullet$ Driving skills $\bullet$ Public safety
}

\section{Introduction}

The impact of car crash injuries on public health is a fundamental issue and its burden growing worldwide (Murray and Lopez, 1997). Indeed, alcohol is recognized as one major factor of driving impairment and car crash injuries (Salim et al., 2009; Talving et al., 2010; Freydier et al. 2014). To reduce alcohol-related accidents and/or injuries, many jurisdictions adopt a legal definition of intoxications based on blood alcohol concentration (BAC) and punish drivers when driving with BAC levels above this limit. The most common and dangerous consequences of alcohol consumption are poor awareness of personal psychological and physical conditions, and lack of awareness of the consequences of one's own behaviour. Furthermore, decreased visual-perceptive ability, reduced reaction time or lack of attention and concentration, poor motor coordination and sleepiness may increase the car crash risk when driving after alcohol drinking. Furthermore sleepiness and alcohol consumption have a combined effect, even low alcohol intake can seriously impair simulated driving performance and risk perception when it is associated with sleepiness (Vakulin et al. 2007). Therefore, alcohol consumption significantly impairs driving performance. The residual effects of recent moderate alcohol consumption ("hangover") on behaviour are still poorly understood (Finningan et al., 2005). Substantially, although hangover may impair task performance, research data are not sufficient to clarify whether hangover actually impairs more complex mental tasks. 
Alcohol produces deficits of many cognitive functions, including executive and motor control processes, which are involved during driving (Montgomery et al., 2012). Some authors (Van Horn et al., 2006) indicated that alcohol selectively suppresses cognitive activity in frontal and posterior parietal brain regions, known to contribute in making inner cognitive models of motor representation and action. Severe chronic use of alcohol has been consistently associated with stable neuropsychological impairments (Loeber et al., 2009), namely in cognitive flexibility, problem solving, decision making, risky behaviour and others (Bechara et al., 2001; Fein et al., 2004; Davies et al., 2005; Noël et al., 2007; Glass et al., 2009; Bernardin et al. 2014). In particular, Glass and coll. (2009) found a clear relationship between alcoholism and a broad range of executive function deficits, as well as with behavioural disinhibition.

Loeber et al. (2009) studied the effects of repeated withdrawals [defined as the number of 24 -h periods of abstinence following a drinking day in the last year) (Glenn et al., 1988)] on cognitive impairment. The authors found that Executive Functions were affected earlier in alcohol abstinence and recovered after longer abstinence; therefore, early age of alcohol drinking or alcohol dependence might increase the frontal lobe susceptibility to the damaging effects of repeated detoxifications (Loeber et al., 2009).

Data regarding neuropsychological parameters in habitual consumers of moderate amounts of ethanol are still controversial. Indeed, the real effect of alcohol consumption on specific cognitive abilities, such as several attentive sub-components mainly involved during driving or operating heavy machineries, need to be studied (Dry et al., 2012).

Aims of the present study were $i$ ) to examine the direct effect of alcohol on attentive functions, normally involved during driving vehicles, and ii) to investigate whether EA blood level lower than 0.5 $\mathrm{g} / \mathrm{l}$ are sufficiently accurate limits to prevent risky behaviours and car crash risk while driving.

\section{Methods}

\section{Ethical approval}

The study was approved by the local Ethical Committee. All procedures were in compliance with the World Medical Association Declaration of
Helsinki. Participants gave informed consent and were free to withdraw from the study at any time.

\section{Participants}

Thirty-two healthy light drinkers, classified according to the National Health and Medical Research Council guidelines (NHMRC; 2001) (up to 14 standard drinks per week for men and 7 per week for women) voluntarily participated to a population-based case control-study conducted at IRCCS Fondazione SantaLucia Rehabilitation Hospital in Rome, from January to December 2009. Participants (16 men and 16 women) were all Caucasian with a mean age of 30.9 years, $\mathrm{SD}=8.3$ and a mean educational level of 16.5 years, SD $=2.2$ ). Only subjects with body weight within $\pm 20 \%$ of the normal range according to gender and height and with body mass index (BMI) below $28 \mathrm{~kg} / \mathrm{m} 2$ were enrolled. Subjects were all native Italian language for better compliance to the study and mild caffeine ( $<5$ cups/ day) and cigarette ( $<10$ cigarettes/day) consumers in order to avoid any symptom due to abstinence during the experimental session.

Exclusion criteria were a history of mental retardation, learning disability, psychiatric or neurological disorders, substance abuse or systemic diseases that might affect the central nervous system, such as arterial hypertension, diabetes mellitus, cardiac, renal and/or hepatic failure, congenital or acquired brain damage, and past or present alcohol or drug dependence (American Psychiatric Association, 1994).

\section{Procedure}

Each participant was randomly assigned to one of the following two groups: one group was submitted to a neuropsychological test battery assessing several attentive functions (i.e. tonic and phasic alertness, selective, divided attention and vigilance), before assuming Ethylic Alcohol (EA-) and, in a separate session, after taking EA (EA+); the second group was first submitted to the neuropsychological assessment after assuming EA (EA+) and, in a separate session, without EA (EA-) in blood.

In detail, in the EA- condition, the subjects' BAC level, measured with breath analyser, was equal to $0 \mathrm{~g} / \mathrm{l}$; in the EA+ condition, subjects drank enough white wine until the BAC level was at least $0.5 \mathrm{~g} / \mathrm{l}$. Participants were tested individually on separate days and sessions, to avoid a combined alcohol/ 
learning effect. Each session lasted 1 hour and half maximum. Tests sessions were hold in a quiet and comfortable room.

\section{Attention tasks}

Test battery for Attentional Performance [(TAP); Zimmermann and Fimm, 1993]

This computerized battery is commonly used to assess different levels of attention, such as tonic and phasic alertness, and vigilance, which are known as intensive components of attention, and selective or divided attention, which constitute the selective components of attention (Van Zomeren and Brouwer, 1994).

Four different tasks were administered: Alertness (Tonic and Phasic alertness), Vigilance (optical vigilance), Go/No-go and Divided Attention (visual and acoustic modalities).

Subjects were instructed to respond to target by pressing the response key as quickly as possible. False alarms and missed answers were recorded as well as reaction time.

During each task, participants placed their arms on an arm rest and held their hand-thumb connected to a $5 \mathrm{~cm} \times 5 \mathrm{~cm}$ response key. The presentation order of the different tasks was given randomly to control a bias due to the presentation effect.

\section{Alcohol measurement and alcoholic sub- stance utilized}

A Dräger Alcotest 6510 was used for quick and accurate breath alcohol analysis.

An Italian white wine ("Verdicchio", 13\% vol.) was administered to all subjects, assumed on a full stomach in quantity sufficient to reach the BAC of 0.5 $\mathrm{g} / \mathrm{l}$ minimum, at the beginning of the $\mathrm{EA}+$ session.

\section{Data Analysis}

In order to avoid any bias due to BAC lowering during testing, the different tests were randomly administered to the different subjects, and the BAC level was measured at the beginning of every subtest.

Data were analyzed on dependent samples, comparing all subjects in the EA- versus the EA+ conditions.

Wilcoxon matched paired test was used to examine changes in variables of interest. For all analyses, SPSS for Windows (Statistical Package of the Social Science, 15.0.) was used.

\section{Results}

All subjects completed the experimental design. Neither gender nor age did affect significantly the performance in any of the cognitive functions tested. Most of the evaluated cognitive functions were sensitive to alcohol level. In fact, the comparison between EA- and EA+ conditions shows significant differences in all the Alertness sub-tests (total, tonic and phasic), in the $R T$ of the Vigilance test and of the Go-NoGo test ( $\mathrm{p}<0.05$ in all cases), as well as in both the sub-components of the Divided Attention test $(R T ; \mathrm{p}<0.001)$ and omitted stimuli $(\mathrm{p}<0.05)$. Only the accuracy in the vigilance test (false responses and omitted stimuli), and in the selective attention test (false responses) was not impaired ( $\mathrm{p}=0.83, \mathrm{p}$ $=0.56$ and $\mathrm{p}=0.21$, respectively).

Table I summarizes the results in both conditions (EA+ vs EA-) for all tests.

\section{Discussion}

This work specifically aimed $i$ ) to examine the direct effect of alcohol on specific attentive functions, normally involved during driving and operating heavy machineries; and ii) to verify whether the Italian law limits for safe driving (EA blood level lower than 0.5 grams per liter) are sufficient to reduce the risk of car accidents.

As shown in Table I, our data revealed that several attentive components (tonic and phasic alertness, selective, divided attention and vigilance) are severely impaired at the BAC levels fixed by the Italian law.

Although BAC levels analyzed in the present study did not affect the accuracy in selecting the target stimuli during tasks testing vigilance and selective attention after alcohol intake, a statistically significant worsening of RT was observed, which might indicate the negative influence of the alcohol in both these attentive components as a whole. The impairment in RT found in our study is in line with previous reports which showed that rising BAC levels can impair response tasks of selective attention and visual search (Abroms and Fillmore, 2004; Fillmore and Vogel-Sprott, 2000). Other authors (Peterson et al., 1990) failed to find any increase in RT after alcohol consumption, probably due to the different 


\begin{tabular}{|c|c|c|c|c|c|c|c|}
\hline & \multicolumn{5}{|c|}{ EA condition } & \multirow{2}{*}{\multicolumn{2}{|c|}{$\begin{array}{c}\text { Comparison betweer } \\
\text { pre-post EA taking* }\end{array}$}} \\
\hline & \multicolumn{2}{|c|}{$\begin{array}{c}\text { Pre-alcohol } \\
\text { (EA-) }\end{array}$} & \multicolumn{3}{|c|}{$\begin{array}{l}\text { Post-alcohol } \\
(E A+)\end{array}$} & & \\
\hline & Mean & SD & $\begin{array}{c}\text { EA } \\
\text { mean (DS) } \\
\text { initial value } \\
(\mathrm{g} / \mathrm{l})\end{array}$ & Mean & SD & Z value & $\mathrm{p}$ \\
\hline \multicolumn{8}{|l|}{ VF Test } \\
\hline Phonemic (corrected score) & 42.75 & 11.33 & \multirow{2}{*}{$0.6(0.2)$} & 38.10 & 11.80 & $-3.158^{a}$ & $<.05$ \\
\hline Semantic (corrected score) & 23.59 & 5.22 & & 20.70 & 5.40 & $-3.206^{a}$ & $<.05$ \\
\hline \multicolumn{8}{|l|}{ TAP Battery } \\
\hline Total Alertness: RT (msec) & 259.94 & 32.92 & \multirow{3}{*}{$0.7(0.1)$} & 279.50 & 38.80 & $-2.959^{b}$ & $<.05$ \\
\hline Tonic Alertness: RT (msec) & 258.33 & 32.98 & & 279.10 & 37.90 & $-3.106^{b}$ & $<.05$ \\
\hline Phasic Alertness: RT (msec) & 257.84 & 27.32 & & 279.00 & 40.20 & $-3.410^{b}$ & $<.05$ \\
\hline Vigilance: $R T$ (msec) & 406.44 & 86.97 & \multirow{3}{*}{$0.6(0.1)$} & 442.50 & 100.40 & $-2.332^{b}$ & $<.05$ \\
\hline Vigilance: false responses & 0.88 & 1.29 & & 1.10 & 2.10 & $-0.210^{b}$ & .834 \\
\hline Vigilance: omitted stimuli & 0.13 & 0.34 & & 0.20 & 0.70 & $-0.586^{b}$ & .558 \\
\hline Go/NoGo: RT (msec) & 479.22 & 55.52 & \multirow{2}{*}{$0.6(0.1)$} & 510.90 & 59.20 & $-3.077^{b}$ & $<.05$ \\
\hline Go/NoGo: false responses & 0.47 & 0.67 & & 0.70 & 0.80 & $-1.252^{b}$ & .210 \\
\hline Divided att.: RT (msec) & 622.81 & 51.40 & \multirow{2}{*}{$0.6(0.1)$} & 685.80 & 74.60 & $-3.774^{b}$ & $<.001$ \\
\hline Divided att.: omitted stimuli & 0.81 & 1.33 & & 1.60 & 1.40 & $-2.753^{b}$ & $<.05$ \\
\hline
\end{tabular}

methodology used in their study. Our data are also in contrast with those of Verster and coll. (2003), who failed to find any impairment in the vigilance performance of occasional drinkers. The authors administered the vigilance test during a hangover condition (the day after alcohol intake), so that the difference between their data and ours could be due to the different methodologies used.

However, some evidence for slower reaction times and higher number of errors has been reported for complex attentive tasks (McCann, et al., 1998; Gouzoulis-Mayfrank, et al., 2000; Fox, et al., 2001a, b). According to Indlekofer and coll. (2009), average RT in combination with a higher incidence of errors may be interpreted as a higher frequency of lapses of attention (i.e., short-term loss of attentional control).

In the present study, we showed that accuracy was sufficiently preserved after assuming alcohol, partially contrasting results of Schweizer and VogelSprott (2008) which found that also the accuracy in cognition tended to be impaired with alcohol, during both the rising and declining BAC levels. However, according to the authors, although such findings raise the possibility that speed and accuracy measure different types or features of cognitive functions, the nature of these processes remains unclear (Schweizer and Vogel-Sprott, 2008). In our opinion, the worsening of RT only, without any impairment in the accuracy of selecting the stimuli in both selective and divided attention, suggest a possible impairment of the intensive component of the attention alone, with a sufficient preservation of the selective component as a whole.

It is well known that human factors are the primary causes of traffic accidents. Among them, attentive disorders may determine daily dangerous situations for the whole community. Indeed, alcohol is only one of the many features that may affect driving behaviour; for example, prolonged and nocturnal vehicle driving, excessive daytime sleepiness, use of mobile phones, sensorial and music hyper-stimulation and, last but not least, use of drugs or psychotropic substances may affect cognitive performances (Garbarino et al., 2014). In particular, Movig and coll. (2004) found an increased risk for single use 
of benzodiazepines or alcohol, or combination of drugs or drugs and alcohol taken together (Poulsen et al., 2012). Cannabis is considered a risk factor in some studies (Lenguerrand et al., 2008) but not in others (Movig et al., 2004), whereas Biecheler et al. (2008) found that alcohol remains the major risk factor at any age, underlining that the combination of cannabis and alcohol represents a priority target for prevention in young drivers.

Observational surveys (McCartt et al., 2006) indicate that an increasing number of drivers use cell phones. Moreover, experimental studies have found that simulated or instrumented driving tasks, or driving while being observed, are compromised by tasks intended to replicate phone conversations, whether using hand-held or hands-free phones, with a relative risk to be involved in a road accident is equal to or higher than 4 (McCartt et al., 2006). Furthermore, Strayer and coll. (2006) have demonstrated that the cognitive impairment due to the use of a mobile phone during the car driving is similar to that provoked by a BAC of $80 \mathrm{mg} / 100 \mathrm{ml}$. Concomitant elevated alcohol levels and the above conditions have been scarcely investigated.

Subjects with previous traumatic brain injury (TBI) are significantly at higher risk of road accidents than age and sex matched normal subjects, likely because of attentive and executive functions disorders (Formisano et al., 2005; Bivona et al., 2012), as well as reduced or lacking in self-awareness (BenYishay et al., 1985; Prigatano et al., 1986; Bivona et al., 2008; Ciurli et al., 2010). Interestingly, it has been demonstrated that subjects with TBI are prone to suffer from excessive daytime sleepiness (Imbach et al., 2015). As an example, subjects with an excessive somnolence are at risk to be involved in a road accident 7 times more frequently than the awake controls (Findley et al., 1988; Garbarino et al., 2001). Our results on the effect of alcohol in normal subjects suggest that the effect of alcohol in subjects with impairment of driving abilities, such as braininjured subjects, may be even more detrimental for personal and social safety, while driving.

The present study is limited by the small sample size, thus larger population studies are necessary to confirm our data.

Expanding the number of participants studied would allow to evaluate EA effects on cognitive functions eventually responsible for risky driving conditions also in more complex situations, such as EA intake combined with cannabis or other conditions like mobile use, or somnolence, previous brain injury or others.

Blood flow and functional imaging techniques, as well as electrophysiological techniques, may contribute to better understand the impact of alcohol on cerebral blood circulation and neural networks changes. For example, Van Horn and colleagues (Van Horn et al., 2006) examined the acute effects of alcohol in the context of goal-directed visuomotor performance during functional magnetic resonance imaging (fMRI), and found that bloodoxygen level-dependent (BOLD) activity in the cerebellum was suppressed after alcohol intake. They also showed that a fronto-parietal network is the most affected by alcohol consumption. Results indicate that alcohol selectively suppresses cognitive activity in frontal and posterior parietal brain regions that, along with cerebellar nuclei, are believed to contribute to the formation of inner cognitive models of motor representation and action. In vivo and in vitro electrophysiological studies (Tu et al., 2007) were used to determine the effects of ethanol on neuronal firing and network patterns of persistent activity of the prefrontal cortex (PFC) neurons. In vivo, ethanol dose-dependently reduced spike activity in the PFC, measured with multielectrode extra-cellular recording in the anesthetized rat. In an in vitro co-culture system containing slices of PFC, hippocampus and ventral tegmental area (VTA), ethanol decreased persistent activity of PFC neurons, but had little effect in cultures lacking the VTA.

The main limitation of the present study is the lack of placebo control group, due to the results of a preliminary pilot study with subjects who showed to be able to recognize alcoholic drinks compared to alcoholic-free drinks. Therefore, the expectancy of receiving EA or alcoholic-free drink could have affected the performance during testing.

In conclusion, our data strongly support the notion that safe drinking equals safe driving. Worsening of attentive functions after assuming alcohol suggests that driving or operating heavy machineries can be severely impaired at BAC level equal to or higher than 0.5 grams per liter. Thus, the increasing burden of car accidents injuries due to alcohol, calls for targeted educational programs involving families, school and public institutions. 


\section{Acknowledgements}

The authors would like to thank Dr. Franco Taggi for his expertise and precious suggestions along the realization of this project.

Thanks also to Marianna Contrada and Marta Aloisi for their editing support.

\section{References}

Abroms B.D., and Fillmore M.T. Alcohol-induced impairment of inhibitory mechanisms involved in visual search. Experimental and Clinical Psychopharmacology, 12: 243-250, 2004.

American Psychiatric Association. (1994). Diagnostic and statistical manual of mental disorders (4th ed.). Washington, DC: Author.

Bechara A., Dolan S., Denburg N., Hindes A., Anderson S.W., Nathan P.E. Decision-making deficits, linked to a dysfunctional ventromedial prefrontal cortex, revealed in alcohol and stimulant abusers. Neuropsychologia, 39: 376-389, 2001.

Ben-Yishay Y., Rattok J., Lakin P., Piasetsky E.B., Ross B., Silver S., Zide E. \& Ezrachi O. Neuropsychological rehabilitation: Quest for a holistic approach. Seminars in Neurology, 5: 252259, 1985.

Bernardin F., Maheut-Bosser A., Paille F. Cognitive impairments in alcohol-dependent subjects. Frontiers in psychiatry, 5: 78, 2014.

Biecheler M.B., Peytavin J.F., SAM Group Facy F., Martineau H. SAM survey on "drugs and fatal accidents": search of substances consumed and comparison between drivers involved under the influence of alcohol or cannabis. Traffic injury prevention, 9: 11-21, 2008.

Bivona U., Ciurli P., Barba C., Onder G., Azicnuda E., Silvestro D., Mangano R., Rigon J., Formisano R. Executive function and metacognitive selfawareness after severe traumatic brain injury. Journal of the International Neuropsychological Society, 14: 862-868, 2008.

Bivona U., D’Ippolito M., Giustini M., Vignally P., Longo E., Taggi F., Formisano R. Return to driving after severe traumatic brain injury: increased risk of traffic accidents and personal responsibility. The Journal of Head Trauma Rehabilitation, 27: 210-5, 2012.

Ciurli P., Formisano R., Bivona U., Cantagallo A., Angelelli P. Neuropsychiatric Disorders in Persons
With Severe Traumatic Brain Injury: Prevalence, Phenomenology, and Relationship With Clinical and Functional Features. J. Head Trauma Rehabil., 26: 116-126, 2011.

Davies S.J.C., Pandit S.A., Feeney A., Stevenson B.J., Kerwin R.W., Nutt D.J., Marshall E.J., Boddington S., Lingford-Hughes A. "Is there cognitive impairment in clinically 'healthy'abstinent alcohol dependence?." Alcohol and Alcoholism, 40: 498-503, 2005.

Dry M.J., Burns N.R., Nettelbeck T., Farquharson A.L., White J.M. Dose-Related Effects of Alcohol on Cognitive Functioning. PLoS One, 7(11), 2012.

Fein G., Klein L., Finn P. Impairment on a simulated gambling task in long-term abstinent alcoholics. Alcoholism, Clinical and Experimental Research, 28: 1487-91, 2004.

Fernàndez-Serrano M.J., Pérez-Garcìa M., Rìo-Valle J.S., Verdejo-Garcìa A. Neuropsychological consequences of alcohol and drug abuse on different components of executive functions. Journal of Psychopharmacology, 24: 1317-32, 2010.

Fillmore M.T., and Vogel-Sprott M. Response inhibition under alcohol: Effects of cognitive and motivational conflict. Journal of Studies on Alcohol, 61: 239-246, 2000.

Findley L.J., Unverzagt M.E., Suratt P.M. Automobile accidents involving patients with obstructive apnea. American Review of Respiratory Disease, 138: 337-40, 1988.

Finningan F., Schulze D., Smallwood J., Helander A. The effects of self-administered alcohol-induced "hangover" in a naturalistic setting on psychomotor and cognitive performance and subjective state. Addiction, 100: 1680-1689, 2005.

Formisano R., Bivona U., Brunelli S., Giustini M., Longo E., Taggi F. A preliminary investigation of road traffic accident rate after severe brain injury. Brain Injury, 19: 159-63, 2005.

Fox H.C., Parrott A.C., Turner J.J. Ecstasy use: cognitive deficits related to dosage rather than selfreported problematic use of the drug. Journal of Psychopharmacology, 1: 273-281, 2001a.

Fox H.C., Toplis A.S., Turner J.J., Parrott A.C. Auditory verbal learning in drug-free Ecstasy poly-drug users. Human Psychopharmacology: Clinical and Experimental, 16: 613-618, $2001 \mathrm{~b}$.

Freydier C., Berthelon C., Bastien-Toniazzo M., Gineyt G. Divided attention in young drivers under the influence of alcohol. Journal of safety research, 49: 13. e1-18, 2014. 
Garbarino S., Nobili L., Beelke M., De Carli F., Ferrillo F. The contributing role of sleepiness in highway vehicle accidents. Sleep, 24: 203-6, 2001.

Garbarino S., Nobili L. Lifestyle and Habits. in Garbarino S., Nobili L., \& Costa G. (Eds) Sleepiness and Human Impact Assessment pp 95-104 Springer Milan. 2014.

Glass J.M., Buu A., Adams K.M., Nigg J.T., Puttler L.I., Jester J.M., Zucker R.A. Effects of alcoholism severity and smoking on executive neurocognitive function. Addiction, 104: 38-48, 2009.

Glenn S.W., Parsons O.A., Sinha R., Stevens L. The effects of repeated withdrawals from alcohol on the memory of male and female alcoholics. Alcohol Alcohol, 23: 337-42, 1988.

Gouzoulis-Mayfrank E., Daumann J., Tuchtenhagen F., Pelz S., Becker S., Kunert H.J., Fimm B., Sasse H. Impaired cognitive performance in drug free recreational ecstasy (MDMA). J. Neurol, Neurosurg. Psychiatry, 68: 719-725, 2000.

Imbach L.L., Valko P.O., Li T., Maric A., Symeonidou E.R., Stover J.F., Bassetti C.L., Mica L., Werth E., Baumann C.R. Increased sleep need and daytime sleepiness 6 months after traumatic brain injury: a prospective controlled clinical trial. Brain, 138: 726-35, 2015.

Indlekofer F., Piechatzek M., Daamen M., Glasmacher C., Lieb R., Pfister H., Tucha O., Lange K.W., Wittchen H.U., Schütz C. Reduced memory and attention performance in a population-based sample of young adults with a moderate lifetime use of cannabis, ecstasy and alcohol. $J$. Psychopharmacol., 23: 495-509, 2009.

Lenguerrand E., Martin J.L., Moskal A., Gadegbeku B., Laumon B. SAM group. Limits of the quasiinduced exposure method when compared with the standard case-control design. Application to the estimation of risks associated with driving under the influence of cannabis or alcohol. Accid. Anal. Prev., 40: 861-8, 2008.

Loeber S., Duka T., Welzel H., Nakovics H., Heinz A., Flor H., Mann K. Impairment of Cognitive Abilities and Decision Making after Chronic Use of Alcohol: The Impact of Multiple Detoxifications. Alcohol \& Alcoholism, 44: 372-381, 2009.

McCann U.D., Szabo Z., Scheffel U., Dannals R.F., Ricaurte G.A. Positron emission tomographic evidence of toxic effect of MDMA ("ecstasy") on brain serotonin neurons in human beings. Lancet, 352: 1433-1437, 1998.

McCartt A.T., Hellinga L.A., Bratiman K.A. Cell phones and driving: review of research. Traffic Injury Prevention, 7: 89-106, 2006.
Montgomery C., Fisk J.E., Murphy P.N., Ryland I., Hilton J. The effects of heavy social drinking on executive function: a systematic review and meta-analytic study of existing literature and new empirical findings. Hum. Psychopharmacol. Clin. Exp., 27: 187-199, 2012.

Movig K.L., Mathijssen M.P., Nagel P.H., van Egmond T., de Gier J.J., Leufkens H.G., Egberts A.C. Psychoactive substance use and the risk of motor vehicle accidents. Accid. Anal. Prev., 36: 631-6, 2004.

Murray C., Lopez A. Alternative projections of mortality and disability by cause 1990-2020: Global Burden of Disease Study. Lancet, 349: 1498-1504, 1997.

National Health and Medical Research Council (NHMRC) (2001) Australian Alcohol Guidelines: Health Risks and Benefits Canberra: NHMRC.

Noël X., Bechara A., Dan B., Hanak C., Verbanck P. Response inhibition deficit is involved in poor decision making under risk in nonamnesic individuals with alcoholism. Neuropsychology, 21: 778-86, 2007.

Peterson J.B., Rothfleisch J., Zelazo P.D., Pihl R.O. Acute alcohol intoxication and cognitive functioning. J. Stud. Alcohol, 51: 114-122, 1990.

Poulsen H., Moar R., Troncoso C. The incidence of alcohol and other drugs in drivers killed in New Zealand road crashes 2004-2009. Forensic Sci. Int., 223: 364-70, 2012.

Prigatano G.P., Fordyce D.J., Zeiner H.K., Roueche J.R., Pepping M., Wood B.C. Neuropsychological rehabilitation after brain injury. Baltimore: Johns Hopkins University Press., 1986.

Salim A., Ley E.J., Cryer H.G., Margulies D.R., Ramicone E., Tillou A. Positive serum ethanol level and mortality in moderate to severe traumatic brain injury. Arch. Surg., 144: 865-71, 2009.

Sano M., Wendt P.E., Wirsen A., Stenberg G., Risberg J., Ingvar D.H. Acute effects of alcohol on regional cerebral blood flow in man. J. Stud. Alcohol, 54: 369-376, 1993.

Schweizer T.A. and Vogel-Sprott M. AlcoholImpaired Speed and Accuracy of Cognitive Functions: A Review of Acute Tolerance and Recovery of Cognitive Performance. Experimental and Clinical Psychopharmacology, 16: 240-250, 2008.

Strayer D.L., Drews F.A., Crouch D.J. A comparison of the cell phone driver and the drunk driver. Hum. Factors, 8: 381-91, 2006.

Talving P., Plurad D., Barmparas G., Dubose J., Inaba K., Lam L., Chan L., Demetriades D. Isolated 
severe traumatic brain injuries: association of blood alcohol levels with the severity of injuries and outcomes. J. Trauma, 68: 357-62, 2010.

Tu Y., Kroener S., Abernathy K., Lapish C., Seamans J., Chandler L.J., Woodward J.J. Ethanol Inhibits Persistent Activity in Prefrontal Cortical Neurons. The Journal of Neuroscience, 27: 4765-4775, 2007.

Vakulin A., Baulk S.D., Catcheside P.G., Anderson R., van den Heuvel C.J., Banks S., McEvoy R.D. Effects of moderate sleep deprivation and lowdose alcohol on driving simulator performance and perception in young men. Sleep, 30: 1327-33, 2007.
Van Horn J.D., Yanos M., Schmitt P.J, Grafton S.T. Alcohol-induced suppression of BOLD activity during goal-directed visuomotor performance. NeuroImage, 1: 1209-1221, 2006.

Van Zomeren A.H. and Brouwer W.H. Clinical Neuropsychology of Attention. New York: Oxford University Press., 1994.

Verster J.C., van Duin D., Volkerts E.R., Schreuder A.H., Verbaten M.N. Alcohol Hangover Effects on Memory Functioning and Vigilance Performance after an Evening of Binge Drinking. Neuropsychopharmacology, 28: 740-746, 2003.

Zimmermann P. and Fimm B. Testbatterie zur Aufmerksamkeitsprufung. Wurselen: PSYTEST, 1993. 